\title{
Performance of elite genotypes of barley, chickpea, lentil, and wheat under conservation agriculture in Mediterranean rainfed conditions
}

\author{
Mina Devkota $^{1, \star}$ (D), S. B. Patil ${ }^{1,2}$, Shiv Kumar ${ }^{1}$, Zakaria Kehel ${ }^{1}$ and Jacques Wery \\ ${ }^{1}$ International Center for Agricultural Research in the Dry Areas (ICARDA), Rabat, Morocco, ${ }^{2}$ University of Agricultural \\ Sciences, Dharwad, Karnataka, India and ${ }^{3}$ International Center for Agricultural Research in the Dry Areas (ICARDA), \\ Cairo, Egypt \\ ${ }^{\star}$ Corresponding author. Email: m.devkota@cgiar.org
}

(Received 19 October 2020; revised 06 April 2021; accepted 28 April 2021)

\begin{abstract}
Conservation agriculture (CA) practices are becoming more important in Mediterranean rainfed areas due to their potential to minimize climatic risk, reduce soil erosion, and improve soil quality and water availability. Due to minimum soil disturbance and crop residue retention, the soil environment for crop growth and development can differ between CA and conventional tillage (CT) practice. However, breeding targets for improving yield performance in CA system remain poorly explored. The objective of this study was to assess the performance of elite genotypes of barley, chickpea, lentil, and wheat grown under CA, a promising alternative agricultural practice in the Mediterranean rainfed conditions. A three-year field study, with contrasting rainfall pattern, was conducted in the International Center for Agriculture Research in the Dry Areas's research field in Morocco to evaluate the tillage $\times$ genotype interaction and its consequence for yield performance of barley, chickpea, lentil, and wheat. Thirteen elite genotypes for each crop were planted under both CA and CT systems. Wheat and chickpea produced significantly higher grain yield ( $+62 \%$ for wheat and $+43 \%$ for chickpea) under CA than in CT, while lentil and barley performed equally under both systems. Significant effect of tillage $\times$ genotype was more frequent for chickpea and wheat than for barley and lentil. Increased yield under CA, mainly in dry year, was associated with higher harvest index (HI). For each crop species yield was mainly influenced by rainfall amount and distribution (75-88\% yield variation), and tillage $\times$ genotype was of little importance. The overall results suggest that a specific breeding program for CA in lentil, chickpea, wheat, and barley may not be efficient. Few tillage $\times$ genotype interaction, especially in dry years, indicated that breeding target on increasing $\mathrm{HI}$, tolerance to drought (high yield in dry years), and potential yield (high yield in wet year) can help to improve yield performance of chickpea, lentil, and wheat genotypes in CA system. Varieties with wider adaptability considering drought tolerance, higher yield with stability, and adoption of CA practices are important in the context of the Mediterranean rainfed environment. Integrating trade-off analysis between yield potential and stability in a rainfall gradient in both CT and CA in the national certification scheme of varieties may be more efficient than developing breeding programs for each type of tillage system.
\end{abstract}

Keywords: Tillage $\times$ genotype interaction; Rainfed drylands; Conservation agriculture; Yield stability; Rainfall; Mediterranean

\section{Introduction}

Crop yield in the rainfed Mediterranean environment, the hot spot for climate change, is highly affected by the rainfall variability, temperature extremes, and low soil organic matter. Conventional agriculture (CA) practice - i.e., intensive soil tillage, residue removal, and mono-cropping - has a negative effect on soil properties, resulting in its degradation and erosion 
(Mrabet et al., 2012; Sombrero and De Benito, 2010). With such an unpredictable weather patterns coupled with conventional tillage (CT), return from the investment in agriculture production is uncertain, which increases the economic risk for the farmers. Healthy soils with high water holding capacity, better-adapted crop varieties, improved crop production practices, and crop rotation are essential for sustainable crop production in such climatic conditions (López-Bellido et al., 1996; López-Bellido et al., 2011). CA practices - i.e., minimum soil disturbance, residue management, and diversified crop rotation - have advantages over CT by reducing cost, increasing water use efficiency, reducing run-off, and soil erosion and increasing soil organic matter without compromising yield (Devkota et al., 2013; Moussadek et al., 2014; Mrabet, 2002). The advantage of CA is more pronounced in rainfed drylands than in humid tropics (Kassam et al., 2012; Pittelkow et al., 2015). Despite several benefits (Ali et al., 2019; Mrabet et al., 2012; Piggin et al., 2015), CA is only practiced on about $2 \%$ of the total cropland in the Mediterranean region. Previous research showed that the effect of CA varies with crop species, varieties, soil type, and environment (Muñoz-Romero et al., 2012; Herrera et al., 2013; Pittelkow et al., 2015). Due to minimum soil disturbance and crop residue retention, the soil environment for crop growth and development can differ between CA and CT practice.

The area under CA practices is increasing in the world (Kassam et al., 2019), but the selection conditions of most breeding programs are not representative of CA (Herrera et al., 2013). Pittelkow et al. (2015) conducted an extensive global meta-analysis of 678 studies, including 50 crops and found that the response to tillage varied widely among crop species and the agroecological environments. For example, the yield of root crops was reduced by $21.4 \%$, while cotton, legume, and oilseed crops showed no yield reduction, and wheat yield reduction was only $2.6 \%$ under conservation tillage. In rainfed dry environments, CA systems performed best with yields for all crop categories equaling or exceeding those under CT. In contrast, Jan et al. (2012) observed a $2 \%$ higher grain yield of chickpea in CT compared to CA in rainfed drylands of Pakistan. Herrera et al. (2013) observed that wheat genotypes with high seedling vigor and resistance to a wide spectrum of diseases performed better under CA. However, developing a breeding program for CA implies first demonstrating a significant interaction between genotypes $(G)$ and tillage $(T)$ for crop yield.

Significant $\mathrm{T} \times \mathrm{G}$ interactions have been observed for wheat (Trethowan et al., 2012; Herrera et al., 2013; Honsdorf et al., 2018; Ruiz et al., 2019). However, other researchers found no significant T $\times$ G for wheat (Carr et al., 2003; Khorami et al., 2018). In three years of evaluation of lentil genotypes under CT and CA in Syria, Shiv Kumar et al. (2011) observed that varietal performance was not consistent in response to the tillage method, and the influence of tillage was driven by weather condition with greater advantage of CA when soil moisture was limiting. Most plant breeding programs are conducted using CT systems; hence, varieties developed for highly favorable growing environments may not perform better under CA conditions (Knapp and van der Heijden, 2018; Kumudini et al., 2008; Newton et al., 2012). To get the full benefit of CA, it is important to develop crop varieties suitable for CA conditions (Herrera et al., 2013; Joshi et al., 2007; Kumar et al., 2011). All these findings clarify that the response of yield to tillage practices for different crop varieties is not simple. The genetic, environmental, and management factors play important roles in crop performance in CA. Few studies have reported tillage $\times$ genotype for wheat, barley, lentil, and chickpea yield in the Mediterranean rainfed drylands. Our study included advanced breeding line for bread wheat (Triticum aestivum L.), barley (Hordeum vulgare), lentil (Lens culinaris, Medik.), and chickpea (Cicer arietinum L.), the major cereal and food legume crops grown in the rainfed Mediterranean, developed by breeding programs of the International Center for Agriculture Research in the Dry Areas (ICARDA). The objective of this study was to evaluate if the interaction between genotype and tillage methods is significant for yield of wheat, barley, lentil, and chickpea and define the targets for improving yield performance of those crops in CA system. 

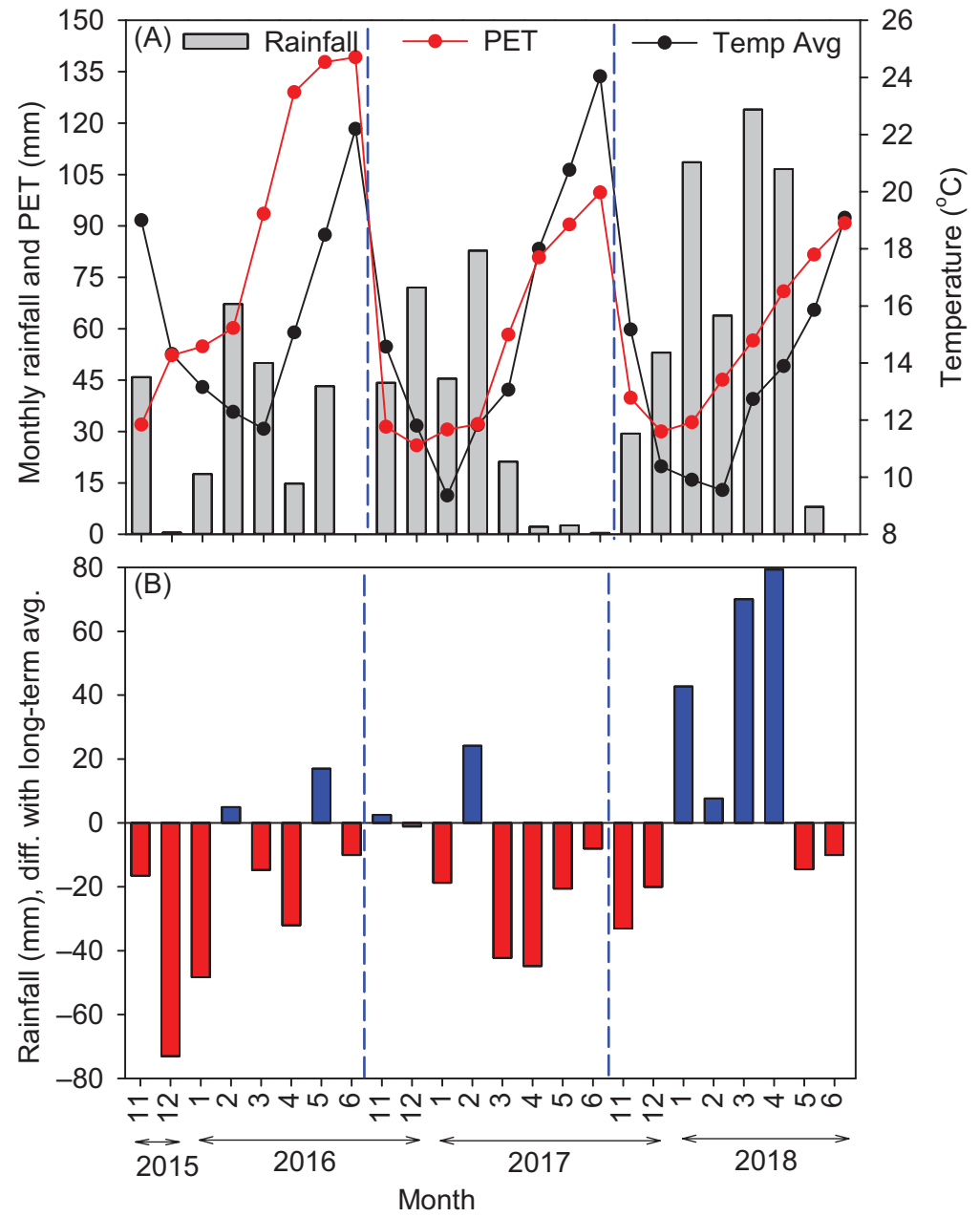

Figure 1. Monthly rainfall, potential evapotranspiration (PET), and mean temperature $(A)$ and monthly variability of rainfall compared to long-term (1974-2019) average for each month (B) during the crop growing seasons (November-June) at the experiment site in Merchouch, Morocco. Numbers in $\mathrm{x}$-axis represent months of the year. Vertical dashed lines indicate growing seasons 2015/16, 2016/17, and 2017/18.

\section{Materials and Methods}

\section{Experimental site}

The experiment was conducted at the ICARDA research farm in Merchouch $\left(33^{\circ} 36^{\prime} 41^{\prime \prime} \mathrm{N}\right.$, $6^{\circ} 42^{\prime} 45^{\prime \prime} \mathrm{W}, 390 \mathrm{~m}$ a.s.l.), $75 \mathrm{~km}$ east of Rabat (Morocco), during the crop growing seasons (December to June) of 2015/2016 to 2017/2018. Growing seasons 2015/2016, 2016/2017, and $2017 / 2018$ are hereafter referred to as 2016,2017, and 2018, respectively. The climate of the region is typically Mediterranean with hot/dry summers and cold/wet winters and highly variable annual rainfall across years. The 45-year (1974-2018) average annual rainfall is $398 \mathrm{~mm}$ with a maximum of $665 \mathrm{~mm}$ and a minimum of $181 \mathrm{~mm}$. Weather parameter was taken from the automated weather measuring device installed in the research station. The average rainfall during the growing season was variable (Figure 1). The mean annual air temperature is $18^{\circ} \mathrm{C}$ with monthly minimum and maximum temperatures ranging within $10-12^{\circ} \mathrm{C}$ and $20-24^{\circ} \mathrm{C}$, respectively. The soil in the experimental site is classified as a Vertisol of clay-loam texture $(47.6 \%$ clay and $41 \%$ loam 
content), with large cracks appearing during the dry season. The soil is low in organic matter content $(1.8 \%)$ and available $\mathrm{K}_{2} \mathrm{O}\left(105 \mathrm{mg} \mathrm{kg}^{-1}\right)$ and high in $\mathrm{P}_{2} \mathrm{O}_{5}\left(65 \mathrm{mg} \mathrm{kg}^{-1}\right)$. Additional soil characters are reported in Supplementary Material Table S1.

\section{Trial design and treatments}

The experiment was conducted for four different crops, i.e., chickpea and lentil for three years (for 2016, 2017, 2018) and barley and wheat for two years (for 2016 and 2017) in a cereal-legume rotation. The experiment was laid out in a randomized complete block design with two replications. The experimental treatment included tillage methods and genotypes of each crop species. The tillage treatment was placed as a fixed factor and 13 genotypes for each crop were randomized within each tillage method. The detailed experimental layout has been presented in Supplementary Material Fig. S1.

The two tillage methods were no-tillage, which had no soil disturbance except for drilling seeds and residue retention; and CT, which includes two to three tillage interventions before sowing and taking out all loose crop residue. The 13 elite genotypes of each crop (chickpea, lentil, barley, and wheat) used in this study were developed by ICARDA breeding programs. Genotypes were selected based on yield potential, early vigor, and maturity earliness. The full list of genotypes and detail characters for all four crop species is presented in Supplementary Material Table S2 for chickpea and lentil and Table S3 for barley and wheat. The selected genotypes of each species were used to screen for yield performance under CA and CT. All the genotypes evaluated were selected under CT conditions. For the easiness in presentation, CA and CT are referred to as tillage methods $(\mathrm{T})$, especially while presenting the interaction effect with genotypes.

The total experimental area was two hectares. To have all crops in each year, the experimental area was divided into two equal parts for both tillage methods. For each crop, half of the area was allocated for genotype evaluation (13 genotypes), and the remaining half area allocated to homogenize the plot by using a commercial variety of the same crop, and crops were alternated in the following year with the following crop (Fig. S1). The plot size for each genotype was $33 \mathrm{~m}^{2}$ $(20 \times 1.65 \mathrm{~m})$. Before beginning the experiment, the field had been cropped with a range of cereal and legume crops under CT systems. CA system was started in 2014/2015 cropping season and planted with a commercial variety of all four crops under both tillage methods.

In $\mathrm{CT}$, the land was prepared according to the farmers' practice: disk plowing for about $10-15 \mathrm{~cm}$ in September followed by one or two shallow tillage using a tine cultivator before seeding. In CA, seed and fertilizers were directly drilled into the undisturbed soil using a zero-till planter. A tractor-mounted six-row heavy plot seeder (Wintersteiger Plotseed XXL) was used for seeding and basal fertilizer application in both CA and CT plots each year. All crops were seeded on the same row spacing of $25 \mathrm{~cm}$, but the seed was calibrated to maintain the number of seeds per $\mathrm{m}^{2}: 300$ seeds $\mathrm{m}^{-2}$ for wheat and barley; 150 seeds $\mathrm{m}^{-2}$ for lentil; and 50 seeds $\mathrm{m}^{-2}$ for chickpea. All crops were seeded on the same day, i.e., on December 15 in 2015 and 2016 and on January 7 in 2018.

Fertilizer application was based on the initial soil nutrient content, and crops received a complex fertilizer ( $15 \%$ each of $\mathrm{N}, \mathrm{P}_{2} \mathrm{O}_{5}$, and $\mathrm{K}_{2} \mathrm{O}$ ) at the time of seeding: $330 \mathrm{~kg} \mathrm{ha}^{-1}$ for cereals (50:22:42 $\mathrm{kg}$ of $\mathrm{N}, \mathrm{P}$, and $\left.\mathrm{K} \mathrm{ha}^{-1}\right)$ and $200 \mathrm{~kg}$ for legumes $\left(30: 13: 25 \mathrm{~kg}\right.$ of $\mathrm{N}, \mathrm{P}$, and $\left.\mathrm{K} \mathrm{ha}^{-1}\right)$. Cereals received an additional $50 \mathrm{~kg} \mathrm{~N}$ through ammonium nitrate $(33 \% \mathrm{~N})$ at the active tillering stage. Weeds during the growing season were controlled by applying selective pre- and post-emergence herbicide and occasional hand weeding. In CA plots, weeds were killed by the application of $1 \mathrm{~L} \mathrm{ha}{ }^{-1}$ glyphosate before sowing. After seeding, pre-emergence herbicide Stomp (455 $\mathrm{g} \mathrm{L}^{-1}$ pendimethalin) was used immediately after seeding, and post-emergence Fusilade (0.75 L ha ${ }^{-1}$ Fluazifop-p-butyl) at 2-3 leaf stage of weeds was applied in lentil and chickpea in both CA and CT plots. In cereals, Mustang 306 SE (2,4-D + Florasulman) was used at the tillering stage to control broad and narrow leaf weeds in both CA and CT plots. 
To measure grain yield, above-ground biomass (AGB) and harvest index (HI) crops were harvested from $4 \mathrm{~m}^{2}$ of land area (four rows with $4 \mathrm{~m}$ length) from each plot and converted to kilograms per hectare. Harvest index was calculated by dividing the grain yield $\left(\mathrm{kg} \mathrm{ha}^{-1}\right)$ by total aboveground biomass $\left(\mathrm{kg} \mathrm{ha}^{-1}\right)$ at harvest. After harvesting quadrats to measure yield, crops were harvested by plot-harvester leaving around $20 \mathrm{~cm}$ straw height from the ground for cereal and 5-10 cm for legumes, and most of the loose residues were removed from both CA and CT plots. At harvest maturity, twenty plants were chosen at random from the center of the plots to determine plant height for all crops. Days to flowering (DF) and maturity (DM) were recorded when more than $50 \%$ of the plants reached flowering and physiological maturity, respectively.

\section{Soil moisture measurement}

Soil moisture at top $30 \mathrm{~cm}$ soil depth was measured for all four crops from both CT and CA plots just before flowering and at harvest. Irrespective of genotype, soil moisture was measured from six points (three points from each replication) each from CA and CT plots. Soil was collected manually using soil-augur and both fresh and oven-dried weight were measured. The gravimetric moisture content was calculated by dividing the mass of water by the mass of dry soil. The gravimetric moisture was then converted to volumetric moisture content by multiplying the soil bulk density of $1.2 \mathrm{~g} \mathrm{~cm}^{-3}$ at $30 \mathrm{~cm}$ soil depth. Bulk density was calculated at the beginning of the experiment as the dry weight of soil divided by its volume. The daily average potential evapotranspiration (PET) was estimated using the excel sheet provided by FAO-56 (Allen et al., 1998) considering the daily measured weather data (solar radiation, $\mathrm{MJ} \mathrm{m}{ }^{-2} \mathrm{~d}^{-1}$; minimum and maximum air temperature ${ }^{\circ} \mathrm{C}$; wind speed $\mathrm{m} \mathrm{s}^{-1}$ measured at $2 \mathrm{~m}$ above the ground level; and relative humidity (\%)) obtained from the automated weather measuring device installed in the research station.

\section{Data analysis}

Data were analyzed using a linear mixed model with residual maximum likelihood (REML). The analysis was run in ASReml (Butler et al., 2009) for R v3.6.0 (R CoreTeam, 2016). A trial was a combination of tillage, genotype, and year (i.e., environment) for each crop. Year, tillage method, genotype, and their interactions were considered as fixed effects. Blocks within each trial were fitted as random to account for field heterogeneity. We also fitted separate residuals per trial to capture the trial-specific error variance. A crop-based combined analysis to assess the genotype $\times$ tillage interaction and a yearly analysis to assess the yearly variation on genotype $\times$ tillage interactions were conducted.

Analysis of variance (ANOVA) and p-values at 5\% were then reported from models for fixed effects. Percent contribution of different factors to the overall trait variation in the experimental series was obtained by partitioning of ANOVA sum of squares and computing the ratio of a variation of a factor to the total variance. The Z-score was calculated for each genotype of all four crops to assess how the overall yield performance deviated from the mean, as shown below:

$$
Z=(X-\mu) / \sigma
$$

where $Z$ is the $\mathrm{z}$-score, $X$ is the mean yield of each genotype over the experimental period, $\mu$ is the combined mean for all the genotypes in the experimental period, and $\sigma$ is the standard deviation.

Yield stability of the chickpea and lentil genotypes under CT and CA was assessed through Additive Main Effects and Multiplicative Interaction Model (AMMI) inbuilt in GenStat software version 20 (VSN International, 2019). The AMMI analysis first fits additive effects for genotypes and environments using the additive ANOVA procedure and then fits multiplicative effects for genotype $\times$ environment by principal component analysis (PCA). All three cropping seasons had contrasting rainfall patterns; hence, an environment was defined as a cropping season (year) for 
PCA analysis. The higher the PCA score, either negative or positive, the more specifically adapted a genotype is to a certain environment. The AMMI stability value (ASV) was derived by GenStat software version 20 and the genotypes with the lowest ASV values are the most stable.

\section{Results}

\section{Environmental conditions during the experiment}

During the crop growing season (November-June) for 2016, 2017, and 2018, the total rainfall was 214, 276, and $509 \mathrm{~mm}$, and the PET was 666,449 , and $447 \mathrm{~mm}$, respectively. Compared to the mean annual rainfall of $398 \mathrm{~mm}$ at the experimental station for 1974-2018, 2016 was the driest year followed by 2017, and 2018 was the wettest (Figure 1A). Total PET highly exceeded the total rainfall for entire growing season (except in February) in 2016 and 2017, mainly later in the growing season (Figure 1A). The monthly rainfall had high variability between and within years, which are the characteristics of the region's climate. During the 2016 season, there was an extremely early-season drought with no rainfall in December and only $17 \mathrm{~mm}$ during January, which affected crop establishment. Although rainfall was below average in 2017, the distribution was uniform during the crop growing season. In the 2016 and 2017 growing seasons, most of the months received low rainfall compared to regional long-term monthly average (Figure 1B). Due to well-distributed rainfall in 2017, yield performance was not affected as in 2016 for all four crops. The mean monthly air temperature had lower variability among years than the total rainfall. The average air temperature during the grain-filling and maturity period (April-June) was cooler in 2018 than in 2016 (by $2-3^{\circ} \mathrm{C}$ ) and 2017 (by $4-5^{\circ} \mathrm{C}$ ) (Figure $1 \mathrm{~A}$ ).

\section{Soil moisture content}

Volumetric soil moisture content on top $30 \mathrm{~cm}$ soil depth was higher under CA plots than in CT for all crops in both crop-growing seasons (2016 and 2017). On average, the soil moisture during flowering (Figure 2A and 2B) and at harvest (Figure 2C and 2D) under CA was higher by 16-20\% in barley, $12-19 \%$ in wheat, $16-29 \%$ in lentil, and $22-25 \%$ in chickpea than in the CT plot (Figure 2). This suggested that CA plots can hold more moisture than in CT. Soil moisture at harvest was fairly low in both tillage methods in both growing season (Figure 2C, 2D). This could be due to occurrence of drought (PET highly exceeded rainfall) during late growing season (March to June) (Figure 1A, 1B).

\section{Grain yield performance}

The strong interannual rainfall variation caused significant differences in grain yield of both cereal and legume crops (Table 1). For all crops, grain yield was significantly low in the year with extreme early-season drought (2016), i.e., no or very little rainfall in December and January, and the highest yield was in the year with a well-distributed amount of rainfall, i.e., 2018. The average yields in 2016, 2017, and 2018 were: 227,587 , and $1756 \mathrm{~kg} \mathrm{ha}^{-1}$ for chickpea; and 297, 997, $1541 \mathrm{~kg} \mathrm{ha}^{-1}$ for lentil. The average yields for barley were 483 and $3072 \mathrm{~kg} \mathrm{ha}^{-1}$ in 2016 and 2017, respectively, and 528 and $2032 \mathrm{~kg} \mathrm{ha}^{-1}$ for wheat (Table 1).

\section{Effect of tillage ( $T$ ) and genotypes (G) on grain yield performance and other traits}

In chickpea, there were significant main (year, $\mathrm{T}$, and $\mathrm{G}$ ) and interaction effects (year $\times \mathrm{T}$ and year $\times \mathrm{G}$ ) on grain yield (Table 2). Grain yield and HI (Table S4) of all genotypes recorded consistently higher under CA plots than in CT (Figure 3A, 3B and 3C). On average, CA out yielded (+43\%) CT in chickpea. In the dry year of 2016 and in 2017, there were significant effects of $\mathrm{G}$ and $\mathrm{G} \times \mathrm{T}$ interaction on chickpea yield (Table 2). The top five yielding genotypes, i.e., CG13, 
Table 1. Grain yield of chickpea, lentil, barley, and wheat under conventional (CT) and conservation agriculture (CA) practices over three growing seasons (2016-2018) in on-station experiments at Merchouch, Morocco

\begin{tabular}{llcrrr}
\hline & & \multicolumn{4}{c}{ Grain yield $\left(\mathrm{kg} \mathrm{ha}^{-1}\right)$} \\
\cline { 3 - 5 } Year & Tillage & Chickpea & Lentil & Barley & Wheat \\
\hline \multirow{2}{*}{2016} & CA & $279 \pm 113$ & $307 \pm 83$ & $664 \pm 418$ & $783 \pm 195$ \\
& CT & $156 \pm 74$ & $287 \pm 80$ & $302 \pm 235$ & $273 \pm 162$ \\
2017 & CA & $636 \pm 717$ & $1,102 \pm 266$ & $2,957 \pm 562$ & $2,385 \pm 455$ \\
& CT & $537 \pm 200$ & $892 \pm 275$ & $3,187 \pm 785$ & $1,678 \pm 486$ \\
\multirow{2}{*}{ Mean } & CA & $2,097 \pm 517$ & $1,512 \pm 421$ & n.a. & n.a. \\
& CT & $1,414 \pm 539$ & $1,570 \pm 488$ & n.a. & n.a. \\
& CA & $1,004 \pm 850$ & $974 \pm 553$ & $1,811 \pm 1,248$ & $1,584 \pm 874$ \\
& CT & $702 \pm 624$ & $916 \pm 617$ & $1,745 \pm 1,554$ & $976 \pm 790$ \\
\hline
\end{tabular}

n.a. $=$ not available.

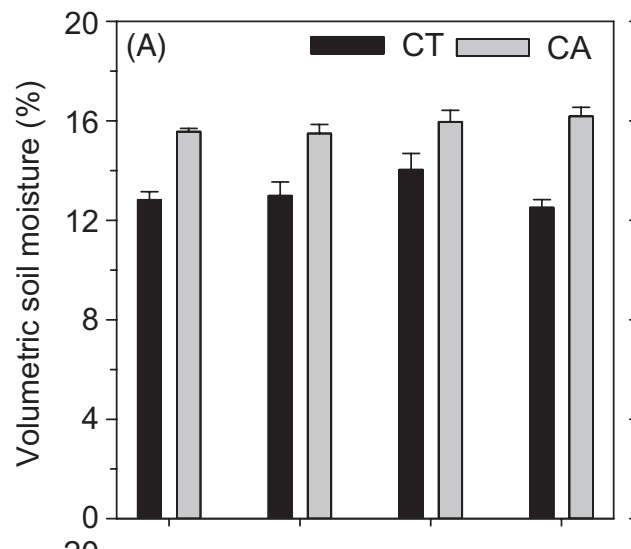

(B)

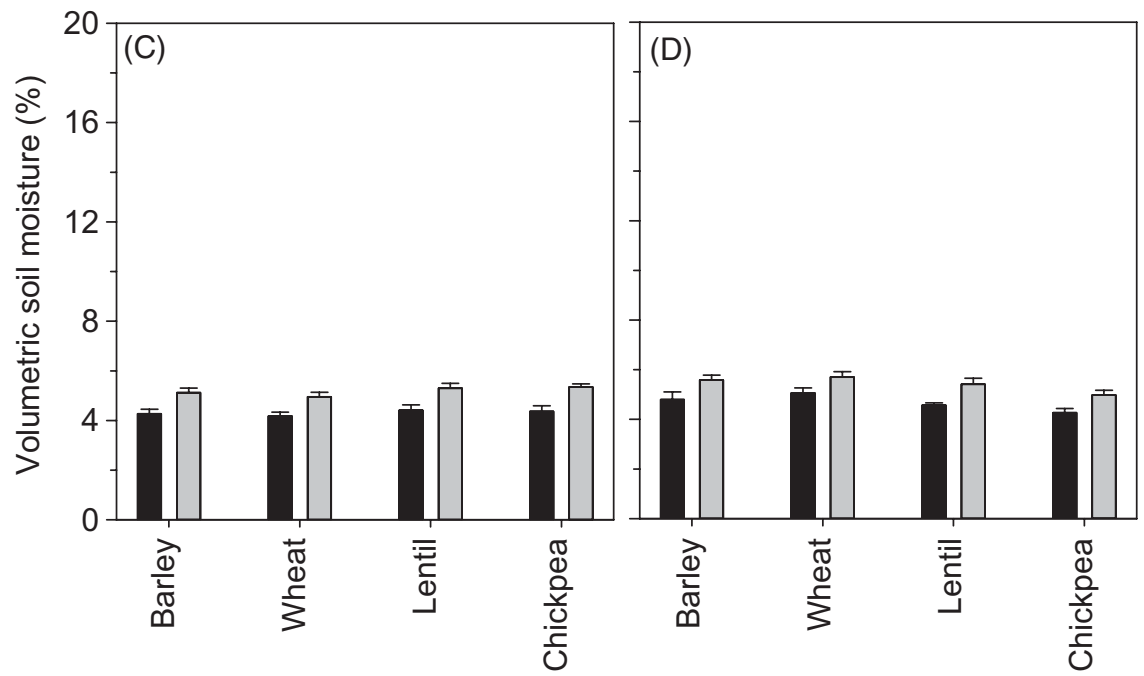

Figure 2. Volumetric moisture content at top $30 \mathrm{~cm}$ soil depth during flowering stage $(A, B)$ and at harvest $(C, D)$ under conservation (CA) and conventional tillage (CT) system for barley, wheat, lentil, and chickpea in 2016 ( $A, C)$ and 2017 (B, D) at Merchouch, Morocco. 
Table 2. Analysis of variance (ANOVA) table for grain yield of chickpea, lentil, barley, and wheat

\begin{tabular}{|c|c|c|c|c|c|c|c|c|}
\hline \multirow[b]{2}{*}{ Treatment } & \multicolumn{4}{|c|}{ Lentil } & \multicolumn{4}{|c|}{ Chickpea } \\
\hline & Combined & 2016 & 2017 & 2018 & Combined & 2016 & 2017 & 2018 \\
\hline Year $(\mathrm{Y})$ & $\star \star \star *$ & - & - & - & $\star \star *$ & - & - & - \\
\hline Tillage $(T)$ & ns & ns & $\star \star \star *$ & ns & $\star \star$ & ns & ns & $\star \star \star *$ \\
\hline $\mathrm{Y} \times \mathrm{T}$ & ns & - & - & - & ** & - & - & - \\
\hline Genotype (G) & $\star \star \star *$ & 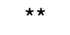 & $\star \star \star *$ & ns & $\star \star$ & 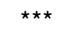 & $\star \star \star$ & * \\
\hline $\mathrm{T} \times \mathrm{G}$ & ns & ns & $\star$ & ns & ns & 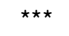 & $\star \star \star$ & ns \\
\hline$Y \times G$ & ** & - & - & - & ** & - & - & - \\
\hline \multirow[t]{2}{*}{$\mathrm{Y} \times \mathrm{T} \times \mathrm{G}$} & ns & - & - & - & ns & - & - & - \\
\hline & \multicolumn{4}{|c|}{ Wheat } & \multicolumn{4}{|c|}{ Barley } \\
\hline Year (Y) & ** & - & - & - & 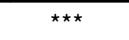 & - & - & - \\
\hline Tillage $(T)$ & * & 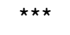 & ns & - & ns & ns & ns & - \\
\hline$Y \times T$ & ns & - & - & - & $\star \star$ & - & - & - \\
\hline Genotype (G) & $\star \star \star$ & * & $\star \star \star$ & - & $\star \star \star$ & $\star \star$ & * & - \\
\hline $\mathrm{T} \times \mathrm{G}$ & $\star$ & $\star \star \star \star$ & ns & - & ns & ns & ns & - \\
\hline$Y \times G$ & $\star \star \star *$ & - & - & - & * & - & - & - \\
\hline $\mathrm{Y} \times \mathrm{T} \times \mathrm{G}$ & ns & - & - & - & ns & - & - & - \\
\hline
\end{tabular}

${ }^{\star} p \leq 0.05,{ }^{\star \star} p \leq 0.01$, and ${ }^{* \star *} p \leq 0.001 ; n s=$ not significant; at $p \leq 0.05$.

CG9, CG7, CG3, CG5, including CG6 and CG10 produced significantly higher yield under CA than in CT in 2016 (Figure 3A). On average, the yield advantage of growing chickpea under CA was in the range of $33-330 \mathrm{~kg} \mathrm{ha}^{-1}$ in 2016. In 2017, genotypes CG7, CG8, CG9, and CG10 produced significantly higher yield under CA than CT (Figure 3B). In the wet year of 2018, the average grain yield and HI were significantly higher under CA than CT (Table 2). In 2018, the top three high-yielding genotypes were CG4, CG6, and CG3 (Figure 3C), and there was no significant $\mathrm{T} \times \mathrm{G}$ interaction. In the dry year, plant height and AGB were higher in CT than in CA (Table 3 and S4). DF and maturity were not affected by the tillage method (Table 3). In the Z-scores analysis, genotypes performing well above and below average varied with tillage methods. In CT, CG4 performed well above average (Z-score of 0.51 ) and CG5 was well below (Z-score of -0.31) (Figure 5A). In CA, CG9 performed well above average (Z-score of 0.31 ), while CG8 was below (Z-score of -0.32), as shown in Figure 5B.

In lentils, across years and genotypes, the average grain yields were similar for CA and CT (974 vs. $917 \mathrm{~kg} \mathrm{ha}^{-1}$ ) (Table 1). There were significant year and genotype effects on grain yield but no significant $\mathrm{T}$ and $\mathrm{T} \times \mathrm{G}$ interaction effects (Table 2). In 2016, with early-season drought, lentil yield varied with genotypes with LG9, LG12, and LG4 being the top three high-yielding genotypes, and LG2 producing low yield (Figures 3D and 4B). In 2017, significant $\mathrm{T} \times \mathrm{G}$ was observed in lentil grain yield (Table 2) and HI (Tables 3 and S5). Irrespective of genotype, 6-61\% higher grain yield was recorded under CA than CT, except for genotype LG7. Out of 13 genotypes, five grown under CA out-yielded CT: LG9, LG5, LG2, LG3, and LG12 (Figure 3E). In the wet year of 2018, non significant $T, G$, and $T \times G$ effects were observed on grain yield (Table 2, Figure $3 \mathrm{~F}$ ). When evaluating Z-scores, LG7 performed well above average (0.44) and LG2 was well below (-0.43) in CT (Figure 5C). In CA, LG6 performed well above average (0.43) and LG2 was below (-0.3) (Figure 5D).

For barley, the average across year and genotypes grain yield was similar for CA and CT (1811 vs $1750 \mathrm{~kg} \mathrm{ha}^{-1}$ ) (Table 1) the combined analysis showed significant year; genotype; year $\times \mathrm{G}$ effects on grain yield of barley (Table 2). There was a significant difference in grain yield among the tested genotypes for barley in both years (Table 2). In 2016 (dry year), BG13 produced the highest yield $\left(971 \mathrm{~kg} \mathrm{ha}^{-1}\right)$ followed by BG5 (909 $\left.\mathrm{kg} \mathrm{ha}^{-1}\right)$ and BG10 (703 kg ha-1) (Figure 3G). In 2017, BG1 (4019 kg ha ${ }^{-1}$ ) followed by BG13 and BG10 (both $\left.3449 \mathrm{~kg} \mathrm{ha}^{-1}\right)$ and BG5 (3373 $\mathrm{kg} \mathrm{ha}^{-1}$ ) were the top four high-yielding genotypes (Figure $3 \mathrm{H}$ ). 

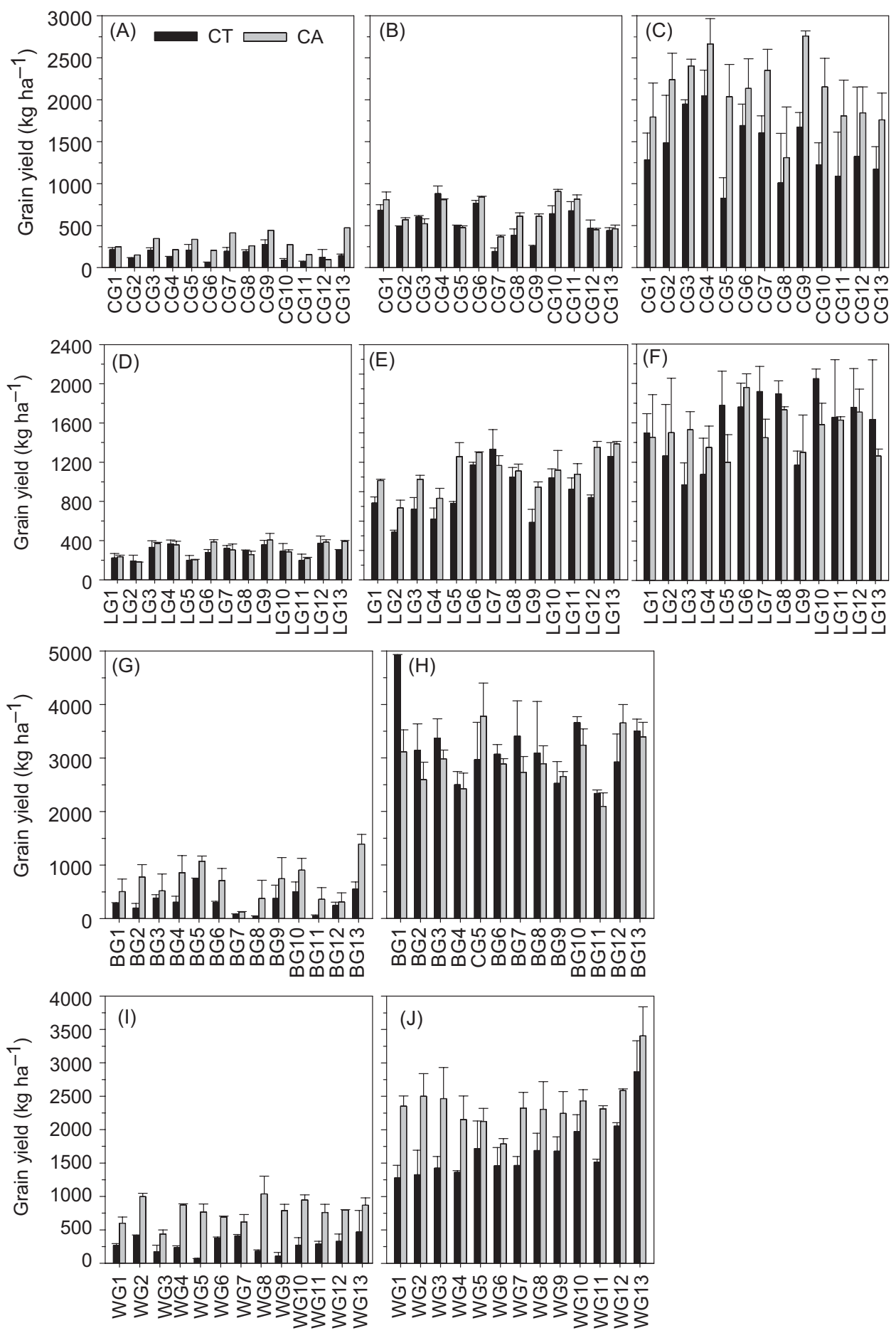

Figure 3. Grain yield of 13 genotypes of chickpea (A, B, C), lentil (D, E, F), barley $(G, H)$, and wheat $(I, J)$ under conventional (CT) and conservation (CA) practices in 2016 (A, D, G, I) and 2017 (B, E, H, J), and 2018 (C, F) in on-station experiment at Merchouch, Morocco. Letters and number in $\mathrm{X}$-axis represent genotypes of respective crops. 
Table 3. Mean values of plant height $(\mathrm{PH}, \mathrm{cm})$, above ground biomass ( $\mathrm{AGB}, \mathrm{t}$ ha ${ }^{-1}$ ), harvest index (HI, \%), days to flowering (DF), and days to maturity (DM) examined for chickpea, lentil, barley, and wheat under conventional (CT) and conservation (CA) practice in two contrast growing season 2016/17 (dry season) and 2017/18 (wet season)

\begin{tabular}{|c|c|c|c|c|c|c|}
\hline \multirow[b]{2}{*}{ Attributes } & \multicolumn{2}{|c|}{ Chickpea } & \multicolumn{2}{|c|}{ Lentil } & \multirow{2}{*}{$\begin{array}{c}\text { Barley } \\
2017 \\
\text { CT/CA }\end{array}$} & \multirow{2}{*}{$\begin{array}{c}\text { Wheat } \\
2017 \\
\text { CT/CA }\end{array}$} \\
\hline & $\begin{array}{c}2017 \\
\text { CT/CA }\end{array}$ & $\begin{array}{c}2018 \\
\text { CT/CA }\end{array}$ & $\begin{array}{c}2017 \\
\mathrm{CT} / \mathrm{CA}\end{array}$ & $\begin{array}{c}2018 \\
\text { CT/CA }\end{array}$ & & \\
\hline $\mathrm{PH}$ & $60.5^{\mathrm{a}} / 54.8^{\mathrm{b}}$ & $68.5^{\mathrm{a}} / 67.4^{\mathrm{a}}$ & $36.4^{\mathrm{a}} / 34.3^{\mathrm{a}}$ & $33.6^{\mathrm{b}} / 36.6^{\mathrm{a}}$ & $96.2 / 90.6$ & $82.8^{\mathrm{b}} / 85.7^{\mathrm{a}}$ \\
\hline$A G B$ & $4.32^{\mathrm{a}} / 2.58^{\mathrm{b}}$ & $6.71^{\mathrm{a}} / 5.53^{\mathrm{a}}$ & $4.51^{\mathrm{a}} / 4.05^{\mathrm{a}}$ & $8.08^{\mathrm{a}} / 5.10^{\mathrm{b}}$ & $10.3^{\mathrm{a}} / 8.35^{\mathrm{b}}$ & $9.49 / 10.53$ \\
\hline $\mathrm{HI}$ & $13^{b} / 25^{a}$ & $21^{\mathrm{b}} / 38^{\mathrm{a}}$ & $20^{b} / 29^{a}$ & $20^{\mathrm{b}} / 31^{\mathrm{a}}$ & $31.2^{\mathrm{b}} / 35.8^{\mathrm{a}}$ & $17.9^{\mathrm{b}} / 22.7^{\mathrm{a}}$ \\
\hline DF & $88 / 88$ & $76 / 75$ & $87 / 87$ & $81 / 81$ & $75 / 76$ & $74.4^{\mathrm{b}} / 76.8^{\mathrm{a}}$ \\
\hline DM & $117 / 116$ & $146 / 145$ & $115 / 116$ & $131^{b} / 139^{a}$ & $122^{\mathrm{b}} / 125^{\mathrm{a}}$ & $124 / 125$ \\
\hline
\end{tabular}
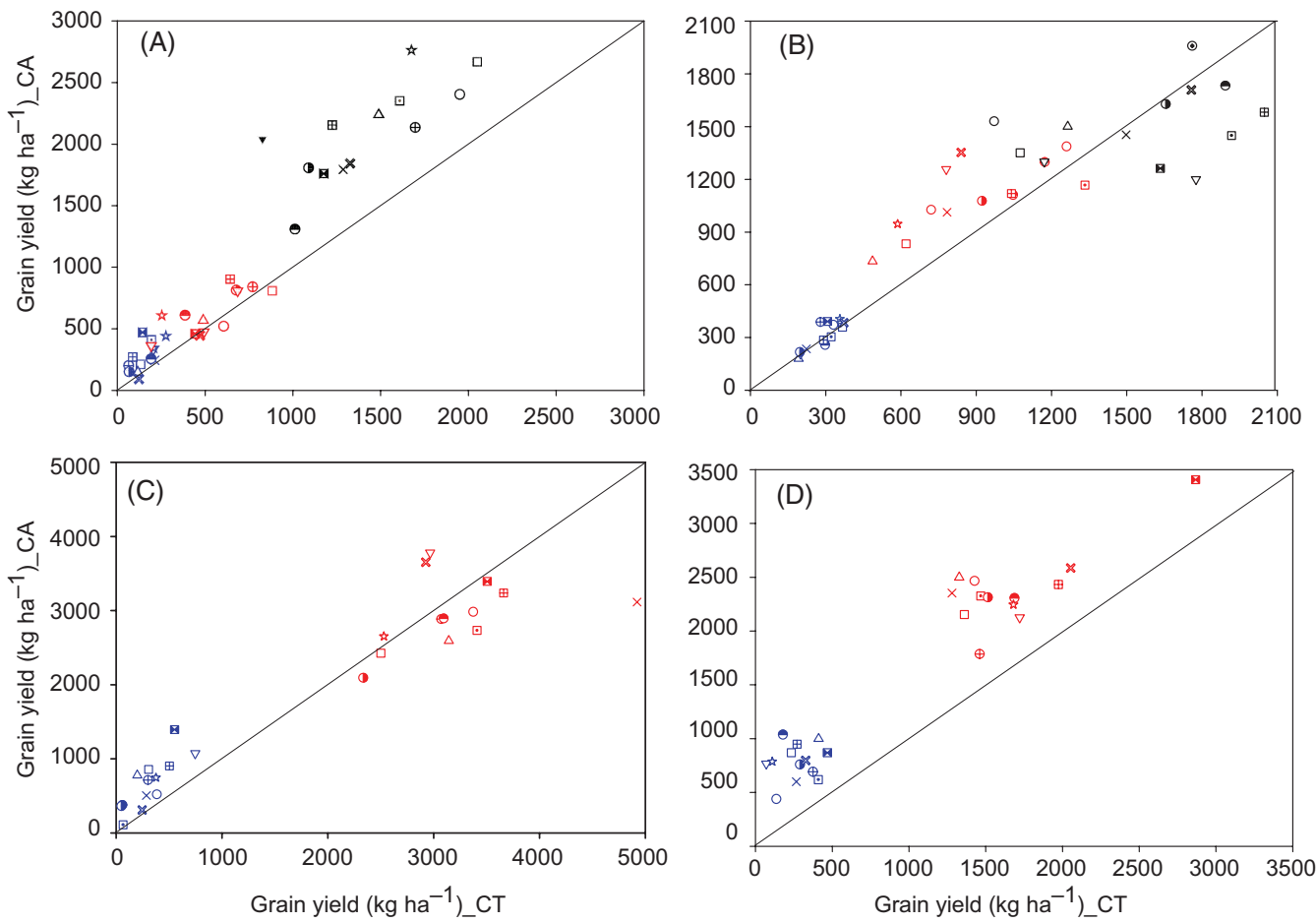

Figure 4. Performance of chickpea (A), lentil (B), barley (C), and wheat (D) genotypes under conservation (CA) and conventional (CT) system during 2016-2018. The solid line shows the 1:1 relationship between CT and CA. Different colors represent the years: blue, 2016; red, 2017; and black, 2018. Symbols denote different genotypes of the respective crop species.

There was no significant $\mathrm{T} \times \mathrm{G}$ effect (Table 2). Irrespective of genotypes, barley grown under CA had low AGB, higher HI, and spent more Days to maturity compared to CT (Table 3). Z-scores analysis revealed BG1 performed well above average (0.55) and BG11 below average $(-0.36)$ in CT (Figure 5E), while BG8 performed above average (0.49) and BG11 again well below average $(-0.46)$ in CA (Figure 5F).

In wheat, the combined analysis showed significant year; genotype; tillage and tillage $\times$ genotype effects on grain yield of wheat (Table 2). Irrespective of the genotype, the average grain yield of wheat was significantly higher (+62\%) under CA than CT $\left(\left(1584\right.\right.$ vs. $\left.977 \mathrm{~kg} \mathrm{ha}^{-1}\right)$ (Table 1). There was a significant influence of genotype on wheat grain yield in both years 

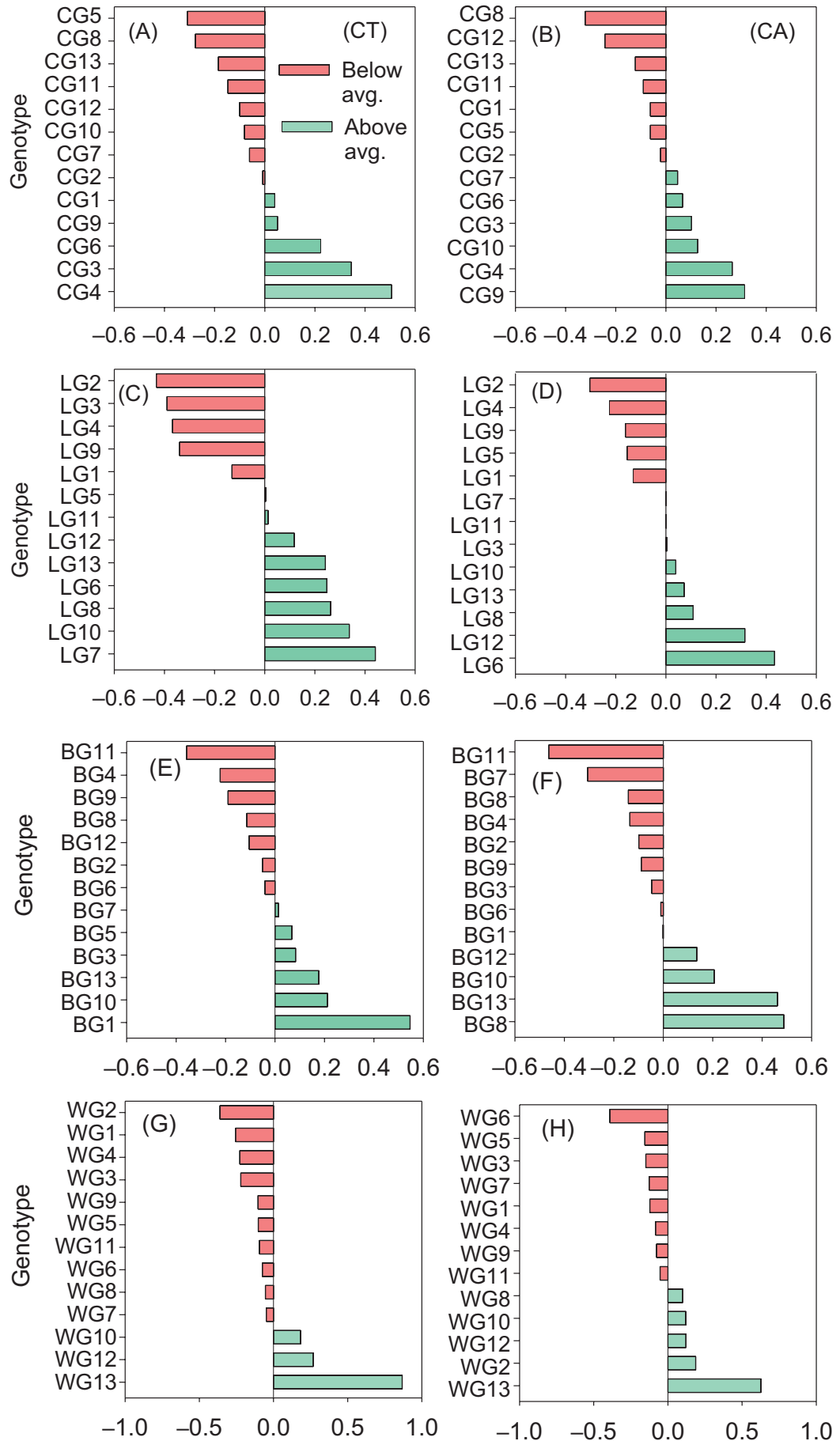

Normalized grain yield (Z-score)

Normalized grain yield (Z-score)

Figure 5. Diverging bar chart to show the yield variance of different genotypes above and below an average yield based on performance of the thirteen genotypes tested under conventional system ( $C T ; 1^{\text {st }}$ column) and conservation system $\left(C A ; 2^{\text {nd }}\right.$ column) over three seasons for chickpea $(A, B)$ and lentil $(C, D)$ and two seasons for barley $(E, F)$ and wheat $(\mathrm{G}, \mathrm{H})$ in Morocco. 
Table 4. Stability indices of thirteen chickpea genotypes under two tillage methods based on grain yield over three cropping seasons (2016-2018) in on-station experiments at Merchouch, Morocco

\begin{tabular}{|c|c|c|c|c|c|c|c|c|c|c|}
\hline \multirow[b]{2}{*}{ Genotype } & \multicolumn{5}{|c|}{ Conventional system (CT) } & \multicolumn{5}{|c|}{ Conservation system (CA) } \\
\hline & ASV & YSI & rAVS & rYSI & Mean & ASV & YSI & rAVS & rYSI & Mean \\
\hline \multicolumn{11}{|l|}{ Chickpea } \\
\hline CG1 & 17.4 & 10 & 5 & 3 & 727 & 33.9 & 18 & 10 & 11 & 951 \\
\hline CG2 & 8.6 & 8 & 2 & 1 & 698 & 19.3 & 12 & 5 & 5 & 986 \\
\hline CG3 & 34.8 & 13 & 11 & 6 & 919 & 29.6 & 11 & 7 & 3 & 1,091 \\
\hline CG4 & 36.0 & 13 & 12 & 7 & 1,020 & 41.4 & 13 & 11 & 7 & 1,230 \\
\hline CG5 & 43.5 & 26 & 13 & 13 & 508 & 6.4 & 11 & 2 & 4 & 951 \\
\hline CG6 & 17.8 & 9 & 6 & 2 & 842 & 9.6 & 8 & 3 & 2 & 1,061 \\
\hline CG7 & 28.1 & 17 & 10 & 10 & 664 & 32.9 & 15 & 9 & 9 & 1,044 \\
\hline CG8 & 25.8 & 19 & 7 & 12 & 529 & 64.2 & 26 & 13 & 13 & 728 \\
\hline CG9 & 28.1 & 13 & 9 & 8 & 734 & 51.8 & 13 & 12 & 8 & 1,272 \\
\hline CG10 & 16.4 & 12 & 4 & 5 & 651 & 12.1 & 7 & 4 & 1 & 1,112 \\
\hline CG11 & 26.9 & 18 & 8 & 11 & 610 & 30.8 & 18 & 8 & 12 & 927 \\
\hline CG12 & 3.1 & 10 & 1 & 4 & 639 & 5.8 & 13 & 1 & 6 & 796 \\
\hline CG13 & 13.9 & 14 & 3 & 9 & 586 & 27.8 & 17 & 6 & 10 & 899 \\
\hline \multicolumn{11}{|l|}{ Lentil } \\
\hline LG1 & 1.81 & 10 & 1 & 5 & 835 & 1.8 & 10 & 1 & 4 & 901 \\
\hline LG2 & 20.2 & 19 & 6 & 10 & 648 & 21.2 & 24 & 11 & 13 & 805 \\
\hline LG3 & 51.3 & 25 & 13 & 13 & 674 & 5.9 & 9 & 3 & 3 & 976 \\
\hline LG4 & 47.1 & 23 & 12 & 12 & 687 & 11.2 & 18 & 6 & 10 & 847 \\
\hline LG5 & 23.2 & 15 & 7 & 9 & 919 & 28.4 & 22 & 12 & 12 & 888 \\
\hline LG6 & 18.9 & 9 & 5 & 3 & 1,071 & 20.5 & 11 & 10 & 5 & 1,215 \\
\hline LG7 & 28.7 & 10 & 9 & 4 & 1,191 & 7.8 & 13 & 5 & 7 & 974 \\
\hline LG8 & 25.1 & 11 & 8 & 6 & 1,079 & 16.2 & 12 & 9 & 6 & 1,034 \\
\hline LG9 & 39.3 & 21 & 11 & 11 & 705 & 13.1 & 19 & 8 & 11 & 884 \\
\hline LG10 & 37.7 & 12 & 10 & 8 & 1,126 & 4.69 & 7 & 2 & 2 & 996 \\
\hline LG11 & 14.5 & 11 & 4 & 7 & 925 & 11.5 & 14 & 7 & 8 & 974 \\
\hline LG12 & 9.71 & 8 & 2 & 2 & 990 & 6.09 & 6 & 4 & 1 & 1,149 \\
\hline LG13 & 13.6 & 8 & 3 & 1 & 1,067 & 33.5 & 17 & 13 & 9 & 1,014 \\
\hline
\end{tabular}

$A S V=A M M I$ stability value, $Y S I=$ yield stability index, $r A S V=$ rank of AMMI stability value, $r Y S I=$ rank of yield stability index, Mean $=$ average yield genotype by environment $\left(\mathrm{kg} \mathrm{ha}^{-1}\right)$.

and the response varied with year. Genotypes WG9, WG12, and WG4 in 2016 and WG13, WG7, and WG6 in 2017 were the top three high-yielding genotypes (Figure 3I and $3 \mathrm{~J}$ ). There was a significant $\mathrm{T} \times \mathrm{G}$ effect on wheat grain yield (Table 2). In both years, all the tested genotypes produced higher yields under CA than CT, with exception of WG7 in 2016 (Figure 3I). Although there was no significant $\mathrm{T} \times \mathrm{G}$ in 2017 , all genotypes yielded more (19-88\%) under CA than CT (3J). This indicated that CA out-yielded CT in wheat for the low rainfall year. Irrespective of genotypes, wheat grown under CA had higher AGB, HI, and longer DF compared to CT (Table 3). Regarding Z-scores, WG13 performed well above average in both CT (0.87) and CA (0.63) (Table 4). WG2 in CT and WG6 in CA were well below average with Z-score of -0.36 and -0.39 , respectively (Figure $5 \mathrm{G}$ and $5 \mathrm{H}$ ).

\section{Genotype stability analysis}

In chickpea, genotype CG12 was the most stable across the three years under both tillage methods (Figure 6A and 6B), with ASV value of 3.1 for CT and 5.7 for CA. The highest yielding genotypes (CG4 in CT and CG9 in CA) were the $12^{\text {th }}$ in terms of stability. Similarly, the most stable genotype was only the $9^{\text {th }}$ in CT and $12^{\text {th }}$ in CA in terms of yield (Table 4). This result showed that the highest yielding genotypes were not necessarily the most stable. In AMMI biplots, a higher number of chickpea genotypes is clustered toward the center in CT than in CA, suggesting genotypes were more stable in CT than in CA (Figure 6C and 6D). In lentil, LG1 was the most stable under 

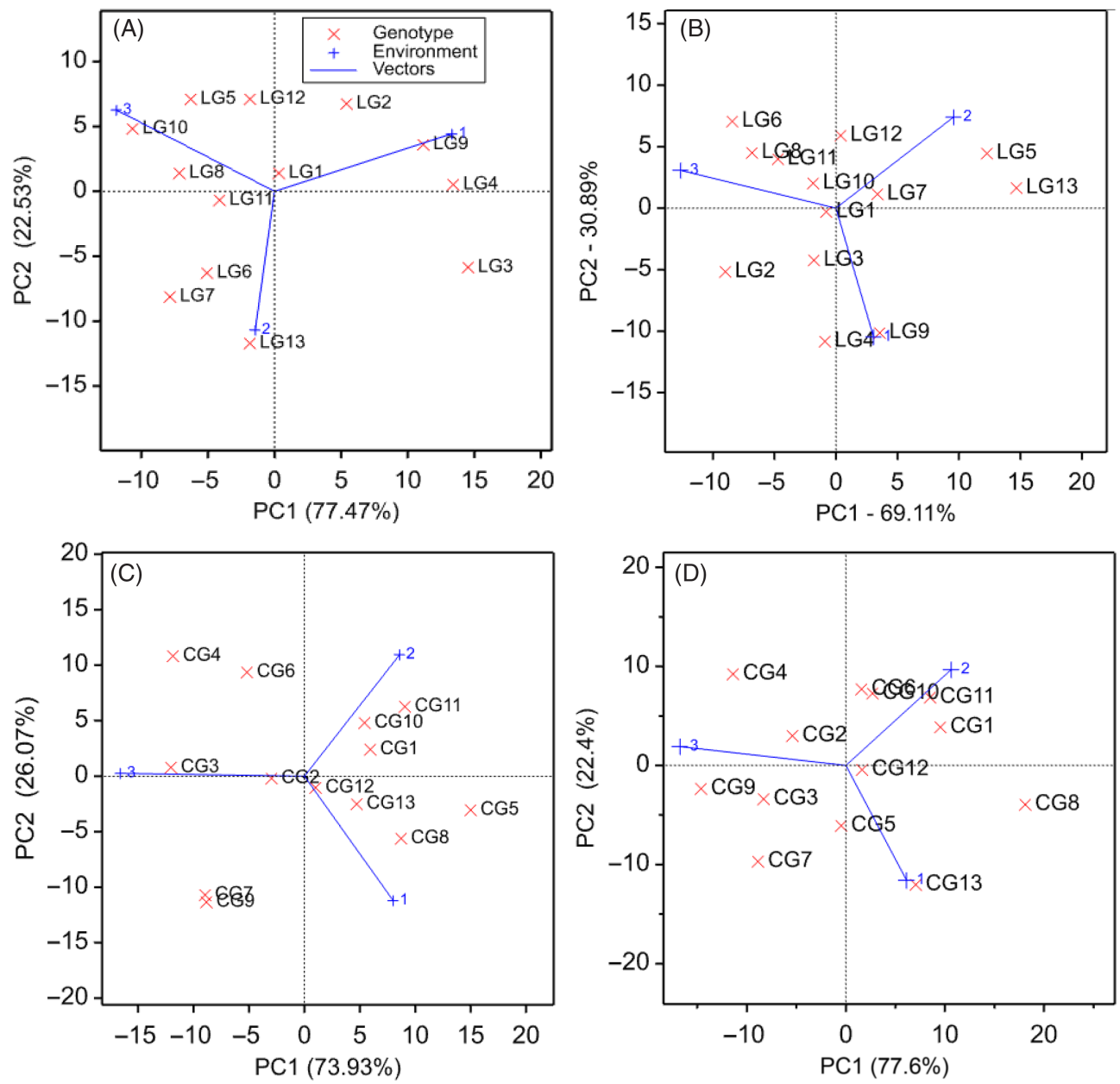

Figure 6. Biplot of the first two axes of the additive main effects and multiplicative interaction (AMMI) model for grain yield $\left(\mathrm{kg} \mathrm{ha}^{-1}\right)$ of thirteen genotype in the three environments (i.e., year) for lentil (A, B) and chickpea (C, D) genotypes grown under and conventional (CT; $A$ and $C$ ) and conservation (CA; B and D) practice.

both tillage methods (Figure 6A and 6B), with ASV value of 1.8. The highest yielding genotypes LG7 in CT and LG6 in CA were the $9^{\text {th }}$ and $10^{\text {th }}$ in terms of stability, respectively. The most stable genotype was only the $9^{\text {th }}$ in terms of yield for both tillage methods (Table 4 ). While these results showed that the highest yielding genotypes were not necessarily the most stable as found for chickpea, a different patter was found in AMMI biplots. More lentil genotypes were clustered toward the center in $\mathrm{CA}$ than in $\mathrm{CT}$, indicating they were more stable in CA than in $\mathrm{CT}$ (Figure 6A and 6B).

\section{Variance components}

In chickpea, the estimates for the variance parameters were significant for the main and interaction effects of year, genotype, and tillage $(\mathrm{p}=0.05)$. About $75 \%$ of the total variation was attributed to the year (environment), $2.4 \%$ to genotype, $2.9 \%$ to tillage, $4.4 \%$ to $\mathrm{Y} \times \mathrm{G}$, and $6.3 \%$ to the $\mathrm{Y} \times \mathrm{T}$ (Table 5). The interaction effects with the year were twice those of the main effects of tillage and genotype. This indicated that the effect of tillage and genotype varied with the year. In lentil, 
Table 5. Variance component estimates $\left(\times 10^{-5}\right)$ for yearly variation $(\mathrm{Y})$, tillage $(\mathrm{T})$, genotype $(\mathrm{G}), \mathrm{Y} \times \mathrm{T}, \mathrm{Y} \times \mathrm{G}$, and error; and their percent contributions (\% cont.)

\begin{tabular}{|c|c|c|c|c|c|c|c|c|}
\hline \multirow[b]{2}{*}{ Parameters } & \multicolumn{2}{|c|}{ Chickpea } & \multicolumn{2}{|c|}{ Lentil } & \multicolumn{2}{|c|}{ Barley } & \multicolumn{2}{|c|}{ Wheat } \\
\hline & Variance & $\%$ Cont. & Variance & $\%$ Cont. & Variance & $\%$ Cont. & Variance & \% Cont. \\
\hline Year & 6.1 & 74.8 & 3.8 & 79.7 & 33.0 & 88.3 & 11.26 & 81.5 \\
\hline Genotype (G) & 0.18 & 2.4 & 0.18 & 3.7 & 0.86 & 2.3 & 0.43 & 3.2 \\
\hline Tillage $(T)$ & 0.22 & 2.9 & 0.008 & 0.2 & 0.01 & 0.03 & 0.92 & 6.7 \\
\hline$Y \times G$ & 0.35 & 4.4 & - & - & 0.61 & 1.7 & 0.39 & 2.8 \\
\hline $\mathrm{Y} \times \mathrm{T}$ & 0.51 & 6.3 & 0.07 & 1.4 & 0.79 & 2.1 & - & - \\
\hline Error & 0.74 & 9.2 & 0.74 & 15.0 & 2.1 & 5.6 & 0.8 & 5.8 \\
\hline
\end{tabular}

the estimates for the variance parameters were also significant $(\mathrm{p}=0.05)$, except for the tillage main effect $(\mathrm{p}=0.5)$. About $80 \%$ of the total variation was attributed to the year and $3.7 \%$ to genotype. The $\mathrm{T}$ main effect accounted for only a small portion $(0.2 \%)$ of the variation in lentil grain yield, while $\mathrm{Y} \times \mathrm{T}$ accounted for more than seven times $(1.4 \%)$ the variation due to the $\mathrm{T}$ main effect (Table 5). This suggested that the grain yield of lentil was more influenced by the yearly variation (i.e., rainfall amount and distribution pattern) than any other factors.

In barley, the estimates for the variance parameters were significant for the year $(p=0.05)$, $\mathrm{Y} \times \mathrm{T}(\mathrm{p}=0.002)$ and $\mathrm{Y} \times \mathrm{G}(\mathrm{p}=0.02)$, but there were no significant main effects of tillage and genotype. About $88 \%$ of the total variation was attributed to the year, $2.3 \%$ to genotype, $0.03 \%$ to tillage, $1.7 \%$ to $\mathrm{Y} \times \mathrm{G}$, and $2.1 \%$ to the $\mathrm{Y} \times \mathrm{T}$ (Table 5). In wheat, the estimates for the variance parameters were significant for the year $(p=0.000)$, tillage $(p=0.000)$, and $\mathrm{Y} \times \mathrm{G}(\mathrm{p}=0.002)$, but there was no significant main effect of genotype. About $81 \%$ of the total variation was attributed to the year and $2.8 \%$ to the $\mathrm{Y} \times \mathrm{G}$. The main effect of $\mathrm{T}(6.7 \%)$ was twice that of the genotype main effect $(3.2 \%)$, indicating a greater response to tillage than genotype (Table 5).

\section{Discussion}

The major variation in grain yield was caused by year in our study (Table 5) indicating that rainfall amount and distribution have a greater influence on crop production in rainfed drylands. Piggin et al. (2015) also observed that the effect of tillage varied markedly with years and crops when evaluating wheat, barley, lentil, and chickpea in Syria. Similarly, Yau et al. (2010) noticed the same pattern of response for barley, chickpea, and safflower in Lebanon.

\section{Effect of tillage on yield performance of legume and cereal crop species}

The higher yield of chickpea under CA than CT in all three contrasting rainfall years (Figure 1), which is also true in wheat (Table 1), might be due to better water availability over longer periods and reduced stress between rainfall events (Figure 2). Yield advantage of growing chickpea in CA in rainfed dryland systems was also reported by Piggin et al. (2015) in Syria and by Hemmat and Eskandari (2004) in Iran. In contrast with our findings, Muñoz-Romero et al. (2012) observed a low yield of chickpea under CA than in CT when rainfall was low, which was attributed to better root growth under CT than in CA in Mediterranean Vertisol soil of Spain. A greater effect of tillage on wheat under water-limited conditions was also reported by Honsdorf et al. (2018) in Mexico. Similar to our study, the higher yield of wheat under CA plot due to greater ability of the CA to hold available soil moisture has also been reported by Ali et al. (2019) and SantínMontanyá et al. (2017) in Mediterranean dryland.

Lentil yield was similar between CA and CT (Table 1) and a negligible contribution of tillage to grain yield (Table 5) indicated that lentil can be grown under CA without yield penalty, which is 
also true for barley (Table 1). In four years of research, Piggin et al. (2015) found no yield difference between CA and CT for barley in Syria and from Mediterranean climate in Spain (Martin-Rueda et al., 2007). However, a significantly higher yield of barley observed in the CA than in CT system in low rainfall with extreme early-season drought (i.e., 2016) (Table 1 and Figure $3 \mathrm{G}$ ) suggesting a yield advantage of CA system in barley when extreme weather event, mainly drought, occurs (Figure 1). A similar result was reported by Cantero-Martınez et al. (2003) in the Mediterranean rainfed conditions in Spain. An increase in grain yield, especially in the dry year, for all four crops grown under CA than in CT (Table 1) indicates that growing these crops under CA is more resilient to variable rainfall than in CT systems. Also, the adoption of CA technology in the rainfed Mediterranean region can be an advantage for the farmers as it avoids the tillage cost, greater ability to hold water (Figure 2), and helps improve soil quality as reported elsewhere (Moussadek et al., 2014; Mrabet et al., 2012).

\section{Tillage $\times$ genotype interaction effects on yield performance}

A significant year and genotype effects for all four crops (Table 2) indicated that genotype performance varied with rainfall amount and distribution. The high yearly variation in genotype performance could be because the tested genotypes were selected for the high-yielding environment; hence their performance was low in the drought year. Few statistical significances in tillage $\times$ genotype interactions were observed in this study (Table 2), likely because the genotypes were exclusively selected under the CT system. The difference in the performance of chickpea genotypes under CT and CA in both dry and wet years (Figure 3A, 3B, 3C), which is also true in wheat (Figure 3I and 3J), suggested the need to identify genotypes according to tillage methods. Although there were significant $\mathrm{T} \times \mathrm{G}$ effects for chickpea in 2016 and 2017, their importance might be small as tillage main effects were not significant in both years (Table 2). However, out of 13 genotypes, four in chickpea and all 13 genotypes in wheat consistently yielded higher with greater $\mathrm{HI}$ in CA than in CT in all years (Figure 3A, 3B, 3C), indicating that selection of genotypes under CA would increase the yield advantage in chickpea and wheat grown under CA. Hence, the adoption of CA with suitable genotypes in chickpea and wheat cultivation can be more resilient in variable rainfall in rainfed Mediterranean conditions. The existence of $\mathrm{T} \times \mathrm{G}$ for wheat, especially in rainfed areas of Central Mexico and the possibility of developing cultivars better adapted to CA, was reported by Trethowan et al. (2012). Compared to the other crops, the contribution of tillage to wheat yield variation was higher (6.7\%) than genotype (3.2\%) (Table 5). These genotypes were selected under the CT system and the use of genotypes selected for CA could further increase the yield benefit of CA in dry years.

In lentil, all genotypes yielded similarly in response to CA and CT in the year with welldistributed and high rainfall, but a significant $\mathrm{T} \times \mathrm{G}$ effect was observed in the year with low but well-distributed rainfall (Table 3, Figure 3E). This indicates that when soil moisture conditions were favorable as in 2018, all genotypes produced well under both tillage systems. However, in low moisture conditions, growing a suitable lentil genotype in CA was advantageous, with the yield advantage of $6-61 \%$ with CA compared to CT (Figures 3E and $4 \mathrm{~B}$ ). This supports the findings from different studies that CA performs best relative to CT under water-limited conditions (Honsdorf et al., 2018; Kassam et al., 2012; Piggin et al., 2015; Pittelkow et al., 2015). Although some interaction effects were found, the contribution of $\mathrm{T}$ and $\mathrm{G}$ was generally minimal, and $80 \%$ of the variation was due to year (Table 5). The chance of increasing yield was similar between CA and CT also justifies that tillage effect was small in lentil.

For barley, no $\mathrm{T} \times \mathrm{G}$ interaction was observed in both years (Table 2), suggesting that a specific breeding focus for tillage may not be efficient. Similar to our result, Ullrich and Muir (1986) also reported no significant tillage $\mathrm{x}$ genotype interaction for yield and plant height for barley in the Northwest of the USA. Authors reported that conventionally developed barley cultivars can satisfactorily grow under no-tillage while conserving soil, water, and energy under warm 
and dry conditions. In contrast with our finding, Newton et al. (2012) observed cultivar-specific effects of soil tillage practices on the yield of barley crops over five years when testing genotypes with contrasting traits. Not many studies on $\mathrm{T} \times \mathrm{G}$ interaction in chickpea, lentil, and barley have been published.

\section{Implications for breeding programs and variety certification schemes}

Few $\mathrm{T} \times \mathrm{G}$ interactions observed (Table 2) could be related to genotypes used in this study which have been bred under CT with good agronomic management (adequate fertilizer, weed, and pest free and with supplementary irrigation, if extreme drought occurs). The growing conditions under on-station experiments are often different from the reality of farmers' fields and their management practices. Hence, it is important to ensure that this breeding process produces genotypes with high yield potential in the wet years and high stability across years to make them attractive to dryland farmers coping against unpredictable variable rainfall.

High rainfall variability with significant downward trends in annual rainfall is occurring in North Africa (Nicholson et al., 2018). In both tillage methods, the most stable genotype ranked low in terms of yield for both chickpea and lentil (Table 4) suggesting tradeoffs between high yield and risk reduction. Quantifying these trade-offs in varieties certification trials and communicating them to farmers may increase the adoption of improved varieties by farmers, and different farmers' type having different risk aversion and capacity to valorize higher productions in the best years.

In a good rainfall year, all genotypes performed well under both tillage systems and some showed higher performances under CA even though they were selected under CT (Figures 3 and 4). These three contrasting years of evaluation do not make clear that if the special breeding focus is needed for varietal development of major cereal and legumes for the CA system. However, it is clear that selection of traits that increase yield in CA, especially in low moisture conditions, could be important for rainfed drylands and are not counter selected for in the current breeding program of ICARDA. Having varieties that can perform well under both type of tillage may also be an advantage for adoption by farmers in rainfed drylands, where CA is still limited and will likely be adopted progressively in a farm and across farms in a region. The assessment of stability with tillage systems in variety certification schemes may therefore also help to support the development of CA in cereals and legumes of rainfed drylands.

\section{Conclusion}

The effect of tillage methods and genotype on yield performance of barley, chickpea, lentil, and wheat varies with rainfall amount and distribution across years in a cereal-legume rotation. Chickpea and wheat produced significantly higher yields under CA systems, but lentil and barley performed equally under both CA and CT in the Mediterranean rainfed conditions. Tillage $\times$ genotype interaction was more frequent for chickpea and wheat than for lentil and barley, but the major cause of variation in grain yield was rainfall amount and distribution. The overall results do not indicate the need for a separate breeding program for CA and CT for chickpea, lentil, barley, and wheat. However, the existence of some tillage $\times$ genotype interaction, especially in dry years, confirmed that breeding targets on increasing $\mathrm{HI}$ and drought tolerance can help to improve yield performance of chickpea, lentil, barley, and wheat genotypes in CA system. Existence of trade-offs between high yield on good years and risk of yield reduction in dry years in both tillage systems suggest that a breeding effort for the development of drought-tolerant and high-yielding genotypes is needed. Thus, varieties with wider adaptability considering drought tolerance, higher yield with stability across rainfall, and tillage systems may improve crop yield in rainfed drylands. Integrating trade-off analysis between yield potential and stability in a rainfall 
gradient in both CT and CA in the national certification scheme of varieties may be more efficient than developing breeding programs for each type of tillage system.

Supplementary material. To view supplementary material for this article, please visit https://doi.org/10.1017/S001447 9721000107

Acknowledgements. The work is supported by the CGIAR Program on Grain Legumes (CRP 3.5) and Wheat - CRP WHEAT (Agreement number 200184). The authors thank the technicians involved in this research.

\section{References}

Ali S.A., Tedone L., Verdini L., Cazzato E. and De Mastro G. (2019). Wheat response to no-tillage and nitrogen fertilization in a long-term faba bean-based rotation. Agronomy, 9, 50.

Allen R.G., Pereira L.S., Raes D. and Smith M. (1998). Crop evapotranspiration-Guidelines for computing crop water requirements-FAO Irrigation and drainage paper 56. Fao, Rome 300, D05109.

Butler D.G., Cullis B.R., Gilmour A.R. and Gogel B.J. (2009). ASReml-R reference manual. Hemel Hempstead, UK: VSN International.

Cantero-Martınez C., Anga, P. and Lampurlanés J. (2003). Growth, yield and water productivity of barley (Hordeum vulgare L.) affected by tillage and $\mathrm{N}$ fertilization in Mediterranean semiarid, rainfed conditions of Spain. Field Crops Research, 84, 341-357.

Carr P.M., Horsley R.D. and Poland W.W. (2003). Tillage and seeding rate effects on wheat cultivars. Crop Science, 43, 210-218.

Devkota M., Martius C., Lamers J.P.A., Sayre K.D., Devkota K.P. and Vlek P.L.G. (2013). Tillage and nitrogen fertilization effects on yield and nitrogen use efficiency of irrigated cotton. Soil and Tillage Research, 134, 72-82. https://doi.org/10. 1016/j.still.2013.07.009

Hemmat A. and Eskandari I. (2004). Tillage system effects upon productivity of a dryland winter wheat-chickpea rotation in the northwest region of Iran. Soil and Tillage Research, 78, 69-81. https://doi.org/10.1016/j.still.2004.02.013

Herrera J.M., Verhulst N., Trethowan R.M., Stamp P. and Govaerts B. (2013). Insights into genotype $\times$ tillage interaction effects on the grain yield of wheat and maize. Crop Science, 53, 1845-1859.

Honsdorf N., Mulvaney M.J., Singh R.P., Ammar K., Burgueño J., Govaerts B. , Verhulst N. (2018). Genotype by tillage interaction and performance progress for bread and durum wheat genotypes on irrigated raised beds. Field Crops Research, 216, 42-52.

Jan A., Amanullah, Akbar H. and Blaser B.C. (2012). Chickpea response to tillage system and phosphorus management under dryland conditions. Journal of Plant Nutrition, 35, 64-70.

Joshi A.K., Chand R., Arun B., Singh R.P. and Ortiz R. (2007). Breeding crops for reduced-tillage management in the intensive, rice-wheat systems of South Asia. Euphytica, 153, 135-151.

Kassam A., Friedrich, T. and Derpsch R. (2019). Global spread of conservation agriculture. International Journal of Environmental Studies, 76, 29-51.

Kassam A., Friedrich T., Derpsch R., Lahmar R., Mrabet R., Basch G., González-Sánchez E.J. and Serraj R. (2012). Conservation agriculture in the dry Mediterranean climate. Field Crops Research, 132, 7-17. https://doi.org/10.1016/j. fcr.2012.02.023

Khorami S., Kazemeini S., Afzalinia S. and Gathala M. (2018). Changes in Soil Properties and Productivity under Different Tillage Practices and Wheat Genotypes: A Short-Term Study in Iran. Sustainability, 10, 3273.

Knapp S. and van der Heijden M.G.A. (2018). A global meta-analysis of yield stability in organic and conservation agriculture. Nature Communications, 9, 3632.

Kumar S., Singh R.G., Piggen C., Haddad A., Ahmad S. and Kumar R. (2011). No till lentil: A profitable option in dry areas. Res. Bull. GRAIN Legum. No. 56 - April.

Kumudini S., Grabau L., Van Sanford D. and Omielan J. (2008). Analysis of yield-formation processes under no-till and conventional tillage for soft red winter wheat in the south-central region. Agronomy Journal, 100, 1026-1032.

López-Bellido L., Fuentes M., Castillo J.E., López-Garrido F.J. and Fernández E.J. (1996). Long-term tillage, crop rotation, and nitrogen fertilizer effects on wheat yield under rainfed Mediterranean conditions. Agronomy Journal, 88, 783-791.

López-Bellido R.J., López-Bellido L., Benítez-Vega J., Muñoz-Romero V., López-Bellido F.J. and Redondo R. (2011). Chickpea and faba bean nitrogen fixation in a Mediterranean rainfed Vertisol: Effect of the tillage system. European Journal of Agronomy, 34, 222-230. https://doi.org/10.1016/j.eja.2011.01.005

Martin-Rueda I., Munoz-Guerra L.M., Yunta F., Esteban E., Tenorio J.L. and Lucena J.J. (2007). Tillage and crop rotation effects on barley yield and soil nutrients on a Calciortidic Haploxeralf. Soil and Tillage Research, 92, 1-9.

Moussadek R., Mrabet R., Dahan R., Zouahri A., El Mourid M. and Ranst E. Van (2014). Tillage system affects soil organic carbon storage and quality in Central Morocco. Applied Environmental Soil Science, 2014, Article ID 654796. 
Mrabet R. (2002). Wheat yield and water use efficiency under contrasting residue and tillage management systems in a semiarid area of Morocco. Experimental Agriculture, 38, 237-248.

Mrabet R., Moussadek R., Fadlaoui A. and Van Ranst E. (2012). Conservation agriculture in dry areas of Morocco. Field Crops Research, 132, 84-94.

Muñoz-Romero V., López-Bellido L. and López-Bellido R.J. (2012). The effects of the tillage system on chickpea root growth. Field Crops Research, 128, 76-81. https://doi.org/10.1016/j.fcr.2011.12.015

Newton A.C., Guy D.C., Bengough A.G., Gordon D.C., McKenzie B.M., Sun B., Valentine T.A. and Hallett P.D. (2012). Soil tillage effects on the efficacy of cultivars and their mixtures in winter barley. Field Crops Research, 128, 91-100. https:// doi.org/https://doi.org/10.1016/j.fcr.2011.12.004

Nicholson S.E., Funk, C. and Fink A.H. (2018). Rainfall over the African continent from the 19th through the 21st century. Global Planet Change, 165, 114-127.

Piggin C., Haddad A., Khalil Y., Loss S. and Pala M. (2015). Effects of tillage and time of sowing on bread wheat, chickpea, barley and lentil grown in rotation in rainfed systems in Syria. Field Crops Research, 173, 57-67.

Pittelkow C.M., Linquist B.A., Lundy M.E., Liang X., van Groenigen K.J., Lee J., van Gestel N., Six J., Venterea R.T. and van Kessel C. (2015). When does no-till yield more? A global meta-analysis. Field Crops Research, 183, 156-168. https:// doi.org/https://doi.org/10.1016/j.fcr.2015.07.020

R CoreTeam, 2016. A language and environment for statistical computing. R Foundation for Statistical Computing, Vienna, Austria, version 3.3. 0. URL Available https//www.R-project.org/ (Accessed Oct. 2017).

Ruiz M., Zambrana E., Fite R., Sole A., Tenorio J.L. and Benavente E. (2019). Yield and quality performance of traditional and improved bread and durum wheat varieties under two conservation tillage systems. Sustainability, 11, 4522.

Santín-Montanyá M.I., Fernández-Getino A.P., Zambrana E. and Tenorio J.L. (2017). Effects of tillage on winter wheat production in Mediterranean dryland fields. Arid Land Research and Management, 31, 269-282.

Sombrero A. and De Benito A. (2010). Carbon accumulation in soil. Ten-year study of conservation tillage and crop rotation in a semi-arid area of Castile-Leon, Spain. Soil and Tillage Research, 107, 64-70.

Trethowan R.M., Mahmood T., Ali Z., Oldach K. and Garcia A.G. (2012). Breeding wheat cultivars better adapted to conservation agriculture. Field Crops Research, 132, 76-83.

Ullrich S.E. and Muir C.E. (1986). Genotypic response of spring barley to alternative tillage systems. Cereal Research Communication, 161-168.

VSN International, 2019. Genstat for windows 20th edition. Hemel Hempstead, UK: VSN International. Web page: Genstat.co.uk.

Yau S.K., Sidahmed M. and Haidar M. (2010). Conservation versus conventional tillage on performance of three different crops. Agronomy Journal, 102, 269-276.

Cite this article: Devkota M, Patil SB, Kumar S, Kehel Z, and Wery J (2021). Performance of elite genotypes of barley, chickpea, lentil, and wheat under conservation agriculture in Mediterranean rainfed conditions. Experimental Agriculture 57, 126-143. https://doi.org/10.1017/S0014479721000107 